\title{
Extenuating Food Integrity Risk through Supply Chain Integration: The Case of Halal Food
}

\author{
Mohd Helmi Ali*, Kim Hua Tan, Kulwant Pawar \\ Business School, University of Nottingham, Jubilee Campus, Nottingham, UK \\ Zafir Mohd Makhbul \\ Faculty of Economics and Management, Universiti Kebangsaan Malaysia, Selangor, Malaysia
}

(Received: February 4, 2014 / Revised: March 10, 2014 / Accepted: March 12, 2014)

\begin{abstract}
Effects of food scandals on religious belief, human health and even on causes of death indicate that firms and consumers are vulnerable to integrity risks in the global supply chain. Mitigating the integrity risk and maintaining the credence quality products like halal food is very challenging, if not impossible. Our aim in this research is to show that supply chain integration can mitigate the halal food integrity risk. To illustrate this idea, we have conducted case studies and interviews in seven Malaysian chicken supply chain focal firms. We unpack the halal integrity risks along the supply chain, such as production risk, raw material risk, food security risk, outsourcing practices risk, service risk, and logistics risk. The research argues that supply chain integration, such as internal integration and external integration practices, could minimize the halal integrity risk. The advantages of supply chain integration in mitigating the halal integrity risk are also highlighted in this paper.
\end{abstract}

Keywords: Halal Food Integrity Risk, Supply Chain Integration

* Corresponding Author, E-mail: mohdhelmiali@gmail.com

\section{INTRODUCTION}

A plethora of food scandals, such as the horsemeat scandal (UK) and 'melamine milk' scandal (China), have shaken public confidence in food integrity. The cases exemplify how concerns are no longer limited to the better quality product and safer food which have been addressed broadly by literature, practices, legislation, regulations and standards (Marucheck et al., 2011; Powell et al., 2013; Roth et al., 2008; Sroufe and Curkovic, 2008). Food integrity is the new horizon of concerns and debates as the recent cases embody this issue. The severity of the cases forces the product to be immediately removed from the marketplace due to pressure from governments and consumers. Misleading labelling on the food appears to be just the tip of the iceberg. However, if the related issues are not being tackled properly and the risk is not being mitigated, they may create a significant impact towards the health, safety and beliefs of the consumers.

The long and complex global food supply chain daunts the task of ensuring food integrity. The situation multiplies the food integrity risks in sustaining product probity as it cuts through various echelons. Currently, the food industry is driven by quality paradigms, such as standards and regulations in mitigating the food quality risk and supply chain vulnerability. However, the mechanism alone will be neither sustainable nor effective in the long run (Roth et al., 2008). In the same essence, the integrity aspects are left out from the mechanism due to the novelty of the concept, and are yet to be comprehended by all (Roth et al., 2008). Furthermore, the tradeoff between the quality and cost concept possibly affects the integrity parameters; some actors in the supply chain cut corners to marginalize their profit.

Seeing this gap, supply chain integration is sought 
to address the food integrity issue. Researchers argue that better supply chain integration is key to better supply chain performance (Flynn et al., 2010; Frohlich and Westbrook, 2001; Rosenzweig et al., 2003) in manufacturing settings. Notwithstanding that the literature shows increase in performance on production and non-production elements, very little is known of the element of integrity tested on the same paradigm. In the light of performance improvement, we see the positivity of the supply chain integration theory and practices in mitigating food integrity risk.

Seen in this context this paper aims to highlight how managers can mitigate food integrity risk through supply chain integration. The paper aims: to conceptually unpack the halal integrity risk framework and to highlight the supply chain integration practices (internal integration and external integration) in mitigating food integrity risk. The paper focuses on halal food based on the following compelling grounds: 1) halal food accounts for more than $17 \%$ of the world food industry (Berry, 2011); 2) halal food shares many important common processes with non-halal food, thus halal food integrity can shed light on other food supply chains; and 3) halal food markets are growing. Improved understanding of halal food risk will have huge practical implications for food firms that intend to venture into the growing markets.

These issues have considerable significance for the field of international business, food supply chain, food risk, food integrity and halal food integrity. Growing halal markets internationally give impetus to firms to ensure halal food integrity and mitigation of risk. Furthermore, strategic application of supply chain integration on food integrity risk is an important aspect of the context of the supply operations management.

The paper begins with a literature review on halal food supply chain integrity risk and motivation of supply chain integrations in mitigating halal food integrity risk. Then it follows up with a methodology section comprising theoretical sampling, data collection and data analysis. Finally, the findings of the studies are explained in a section on halal food integrity risk and mitigating halal food integrity risk through supply chain integration before the conclusions.

\section{LITERATURE REVIEW}

This section consists of two subsections. It starts with a description of the halal requirement, uniqueness of halal food supply chain, and halal food supply chain integrity risk, and continues by highlighting why supply chain integration is selected in addressing the halal integrity risk.

\subsection{Halal Food Supply Chain Risk}

Risk is often described in a situation which would lead to negative consequences. A more standard definition of risk is: the chance, in quantitative terms, of a defined hazard occurring. Supply chain risk is "The potential occurrence of an incident or failure to seize opportunities with inbound supply in which its outcome results in a financial loss for the purchasing firm" (Zsidisin et al., 2006). Moreover, the scope of understanding supply chain risk varies according to industries, and halal food integrity risk in a supply chain is the risk of producing a halal food product that has not fully adhered to the halal guidelines and requirements.

Halal food products are credence quality attributed products, in which the characteristic of the product cannot be evaluated or ascertained by the individual customer, even after consumption of the same (Bonne et al., 2007). Looking from this perspective, the risk of integrity of the food is very significant. For instance, in determining halal food integrity, the following conditions shall be conformed to during halal food production (Sumali, 2006):

- The food or the ingredients shall not contain any parts or products of animals that are non-halal to Muslims by Islamic law, or products of animals which are not slaughtered in accordance with the Islamic law.

- The food does not contain any ingredients that are Najis (ritually unclean) as per Islamic law; the food is safe and not harmful, and clean.

- The food is not prepared, processed or manufactured using equipment that is contaminated with things that are Najis as per Islamic law.

- The food or its ingredients do not contain any human parts or its derivatives that are not permitted by Islamic law.

- During preparation, processing, packaging, storage or transportation, the food is physically separated from any other food that does not meet the definitions stated in the items above, or any other things decreed as Najis by Islamic law.

In addition, halal food producers are required to apply the thoyibban concept, encompassing quality, nutrition, hygiene, and ethically delivered the product to the consumer (Othman et al., 2009). Furthermore, in literature and in practice, Halal Critical Control Points (HCCP) are highlighted and used as additional measures and guidelines for halal food production, respectively (Guerrero-Legarreta et al., 2010; van der Spiegel et al., 2012).

In doctrine, the halal food supply chain risk shares the same fundamental principles as other food supply chains, e.g., the 'farm to fork' concept (Manzini and Accorsi, 2013; Tuncer, 2001). Fraud and misconduct in the halal food supply chain do not have immediate and lethal impacts, such as towards health and life. Moreover, to date there are very limited scientific ways to ascertain whether the food is halal or not ( $\mathrm{Ab}$ Talib and Johan, 2012). In the light of this, ensuring halal food 
integrity in the complex global food supply chain is very challenging, if not impossible. Despite the enforcement of halal certification, standards, regulation, and legislation as controlling mechanisms for halal food, the approaches are not a panacea (Roth et al., 2008). In particular, the empirical evidence of other standards and certification shortfalls is high, and probably impact the halal food industry in the same manner (Gotzamani, 2005; Powell et al., 2013; Sroufe and Curkovic, 2008) Intensifying that, the halal certification process is not standardized internationally and yet it is implemented on a larger scale than nationally.

Globalized supply chains increase the complexity of halal food integrity. The halal integrity risk is enormous when the suppliers or sub-suppliers are located overseas, especially in non-Muslim countries where the involvements of non-Muslims are unavoidable. Referring to the recent food integrity scandal of horsemeat in the United Kingdom (2013) which involving major player in the food industry, the integrity problem is still prominent. As argued by Tseng and Chiu (2013) in green supply chain context, suppliers normally have long-term contracts with the users and provide their services for multiple functions or develop close service with customer. Despite the existence of the mechanism in the supply chain, the weak links in multi-tier sourcing; higher tier suppliers outsourced to sub-tier suppliers is still to blame as the cause of the scandal. The case indicates that the long and wide (multiple product used for the production) supply chain resulted in complicating the tracking of quality control in the supply chain (Lyles et al., 2008). It is more significant to the halal food industry due to incomprehensiveness of the novel halal and integrity concept.

\subsection{Motivation of Supply Chain Integration in Mitigating Halal Food Integrity Risk}

Supply chain integration is a relatively new area of research (Flynn et al., 2010). However, there is an extensive body of research arguing that supply chain integration leads towards performance improvement (Flynn et al., 2010; Frohlich and Westbrook, 2001; Swink et al., 2007). Moreover, the supply chain integration literature focus widely on the manufacturing industries, and very little known studies have been conducted in food industries. Seeing the positivity of the supply chain integration impact and the lack of studies in food supply chains, we build upon the existing literature on the supply chain integration construct, including the focal firm (internal integration), and extend it beyond the firm's wall (external integration). Internal integration recognizes that different departments and functional areas within a firm should operate as part of an integrated process (Flynn et $a l ., 2010)$. The internal integration focuses the activities within the firm, i.e., organizational strategies, practices and processes into a collaborative, synchronized process in safeguarding the customers' requirements. Meanwhile, external integration is the degree to which a focal firm with its external partners structure inter-organizational strategies, practices and processes into collaborative, synchronized processes. As both types of integration play different roles in the context of supply chain integration (Flynn et al., 2010), it is important to highlight these within the study context.

The supply chain integration provides new insights for the decision makers in the firm to mitigate halal food integrity risk. The information obtained from the integration is more valuable than a piece of halal certification. Consider the following example: the current supplier selected provides a product with a halal certification, with a cost of chicken at US $\$ 2 / \mathrm{kg}$. Table 1 depicts the alternatives for the supplier selection when there are no integration between buyer and seller.

However, in the effort of determining halal integrity, the additional information as per Table 2 which highly possible to be obtained from the integration changes the perspective of halal integrity risk is higher with the current supplier. In this essence, as argued by Tse and Tan (2011), the length of supply chain and unseen processed outsourced increased the risk of the quality.

The example is undeniably trivial, but the insight of the halal integrity risk gained from the supply chain integration is very valuable, especially in situations where the credence quality product cannot be ascertained concurrently.

Moreover, we believe supply chain integration can address the shortcomings of the existing control mechanism. The mechanism-based approach assumes that the certified suppliers are at all times capable of representing the halal issue, and interactions associated with its problems. The trade-off between the cost and extra quality productions always pushes the profit oriented company to cut corners, especially when it is associated with a fresh concept like integrity, which is hard to comprehend by all (Roth et al., 2008). The supply chain integration allows decision makers to gain better insight into the issues; seen in this pattern, this paper will incorpo-

Table 1. Traditional information during halal buying selection

\begin{tabular}{ccc}
\hline Supplier & Cost $/ \mathrm{kg}($ USD) & Halal certified \\
\hline Current & 2.00 & Yes \\
A & 2.10 & Yes \\
B & 2.15 & Yes \\
\hline
\end{tabular}

Table 2. Additional buying information may be obtained through integration

\begin{tabular}{ccc}
\hline Supplier & Length of supply chain (tier) & Process outsourced \\
\hline Current & 3 & 2 \\
A & 2 & 1 \\
B & 1 & 0 \\
\hline
\end{tabular}


rate supply chain integration for managing the halal integrity risk.

\section{METHODOLOGY}

The research seeks to build a conceptual theory rather than testing the existing one. In light of this, case study is an appropriate method for theory development in dealing with complex research fields, e.g., supply chain management (Dubois and Araujo, 2007) and for better understanding of the phenomenon's complexity and nature (Stuart et al., 2002).

\subsection{Theoretical Sampling}

This study focuses on halal food supply chain in the Malaysian context. Theoretical sampling is done through identifying the focal companies which are characterized by: 1) halal certified company (voluntary basis certification); and 2) private limited status. Concentration is given to the focal companies listed by JAKIM (Government of Malaysia's halal certification body) as halal certified and which use chicken and beef in their supply chain. The comparability issues are tackled through the selection mix of focal companies that produce only halal products, with headquarters in Malaysia (i.e., applying similar regulations and standards), are brand owners of the products, with similar status of the company, and global scope of their supply chain. A selection of similarly ranked companies was contacted. Through the process, seven companies from different consumers' preferences agreed to participate. All companies are leading brands in different settings of consumer preference. The selection of the focal company's respondents was done through the listed contact person obtained from the JAKIM database. As a general criterion, the companies must be significantly active with the certification. The highest risk was bias, which was prevented by not naming the companies participating in the study. In total the paper analyzed seven supply chains, which fell within the often suggested sample size of four to ten cases (Eisenhardt, 1989).

\subsection{Data Collection}

For every sampled case, in-depth interviews with the key informant from the focal company were conducted. The interview questions were adopted from existing literature but with a halal perspective (Frohlich and Westbrook, 2001; Ketchen and Hult, 2007; Ragatz et al., 2002; Wong et al., 2011). The interviews were done in the English language preceded by an email notification. Each interview ranged from 45 minutes to 2 hours. All interviews were audio taped and accompanied with comprehensive note taking and transcribed afterwards. The triangulation of the insights was accompli- shed through several alternative data sources, i.e., corporate website and annual reports.

\subsection{Data Analysis}

Data analysis was done in two stages. Within-case analysis was done to examine the halal integrity in a single context; meanwhile the across-case analysis was done in order to replicate testing of the construct of interest in the other setting. Description consistency of each case was generated through within-case analysis by capturing all relevant information on the focal company management related to the halal integrity. A few steps were taken during the data analysis phase. Firstly, the field notes were written up before being consolidated and coded. Then, multiple researchers reviewed the field notes and any inconsistencies between the individuals were clarified through follow-up contact with the firm's informant. Secondly, the paper limited the categorization of the individual case on previously identified constructs. Case analysis consisted of looking for data patterns regarding focal company experiences with halal integrity across the focal companies. Excel tables were used to facilitate the comparison of several possible dimensions (Miles and Huberman, 1999). Data reduction was accomplished primarily through categorization. Next, the equivalent of a tree node system was used as a way of hierarchical indexing-categorizing nodes. The result was then grouped into two integration strategies (Frohlich and Westbrook, 2001) in addressing the halal integrity. Subsequently, one member of the research team who was not involved in initial data collection was asked to verify the analysis.

\section{HALAL INTEGRITY RISK IN THE FOOD SUPPLY CHAIN}

This section highlights and defines six dimensions of halal integrity risk: production, raw materials, food security, outsourcing practices, service, and logistics.

\subsection{Production}

The production of halal food is governed by standards and legislations. In the same essence, halal food production is vulnerable to different risks at different stages, and the focal companies are held responsible for the activities along its supply chain. In the long and complex halal food supply chain and according to the insights of focal firms, production is the most emphasized stage in determining the quality of the food for the customer. Referring to this, the study highlighted the most significant risk during the production stage - contamination from non-halal elements used in halal certified ingredients: 
"(․) recently JAKIM (Malaysian Halal Certification Body) found a swine's DNA in the coffee ( $\cdots)$ " (case $E)$ and

"( $\cdots)$ in the year of 2012, a halal certified butter founded containing prohibited elements (swine's $D N A$ ). We do not use the butter, but through flyers, JAKIM instruct the firm using it to conduct a ritual cleaning (sama)" (case A).

The insights signify the hidden halal integrity risk during the production stage on the ingredients' halal status instability. Ideally, the production of halal products cannot commence without halal certification covering the ingredients used. On average, certification renewal is done every two years by JAKIM and six months' lead time is required for the new halal certification application. Seen in the divarication of time and the ingredients' instability, there are probabilities of changes to the elements associated with the products such as suppliers' halal status, ingredients' halal status, etc., than on those submitted and certified. Thus, slight changes in the ingredients risk the integrity of the food which was certified as halal previously. Furthermore, the firms' internal quality management systems cannot adhere to all the ingredients updates automatically, and require vigilant monitoring by qualified personnel.

On the other hand, halal production is also exposed to the risk of contamination from the equipment, which eventually affects halal integrity. For example, the origin of materials for food packaging are questionable, especially when unknown animal origins are used such as in the oil, fats or gelatines commonly found in the production of plastic and cans (Ab Talib and Johan, 2012). Case $\mathrm{C}$ highlighted the risk of prohibited equipment, and that the use of appropriate equipment should be not only limited to the factory and kitchen sections, but be applied to all the echelons along the supply chain.

\subsection{Raw Materials}

All the cases highlight the concern over the halal integrity of the supply of their raw materials. Globalized food supply chain benefits such as higher availability make halal food not exempt from sourcing imported raw materials. However, very few countries other than Malaysia are implementing halal food certification and standards through the government's involvement, e.g., Brunei. The other countries are still dependent on the halal food private associations. Despite foreign certificates' recognition by JAKIM being in place, doubt on halal food integrity cannot be eliminated:

“( $\cdots)$ is facing problems regarding controlling the imported raw materials and we are unable to fully ensure the raw materials sourced are halal' (case F).

On the contrary, the absence of traceability tools leads towards the over reliance of the halal certification, but weak enforcement by responsible authorities on fraudulent halal logos and certificates complicates its reliability (Muhammad et al., 2009). The swarming issues around the raw materials and certification suggest the risk of halal integrity in raw materials is eminent (Ab Talib and Johan, 2012). Aggravating that, the conformances of halal certification practice are only deployed at the very early stage of the supplier's appointment. Moreover, the certification is issued per production, a shortfall which increases the threat of risk to halal integrity as the visibility of the long supply chain cannot be determined, especially when there is a low traceability of material origins (Tse and Tan, 2011), which has an effect towards the safety aspects of the materials.

On the other hand, added quality in a product directly increases the cost and initiates the trade-off between the certified and non-certified suppliers. Exemplifying this is the dilemma of the firms who choose between sourcing from the 'known' halal abiding supplier, majority namely small or medium enterprises without halal certificate and a lower cost, and bigger scale enterprises equipped with halal certification but offering a supply at higher price. Such situations impair the judgement and decision for the profit oriented firms who are looking to stay competitive. In the same essence, recognition of certain standards leads towards rigidity in the firm's supplier selections, which is a double-edged sword for the halal food industry:

“(‥) we are following HCCP, so we select our supplier with HCCP requirements only to reduce risk $(\cdots)$ " (case G).

\subsection{Food Security}

Supplier selection rigidity has increased the risk of halal food integrity. Such rigidity leaves little room for the firm to leverage the potential source available in the market. Intensifying this, the immature local halal food industry causes the firm to source from the international market:

“( $\cdots)$ we are depending on the supplier from overseas as the local supplier is seems unable to help and meet the requirement (certification) ( $\cdots$ ) the industry is immature ( $\cdots)$ " (case D).

In the same essence of the aforementioned trade-off between 'known' supplier and certified supplier, halal food security can be breached due to unexpected situations, such as unusual and/or seasonal demands, product shortages, poor management, and price fluctuations of certain raw materials in the small local market. Despite this being arguable on the frequencies of the occurrences, the food security risk is pertinent to halal food integrity due to the credence quality of the product and the complexity of the halal food supply chain (Marucheck et al., 2011). Moreover, due to the absence of 
standardized halal certifications internationally, confirming halal certifications and suppliers' processes become a daunting task for the focal firm. Notwithstanding the recognition of certification bodies is partially practiced in order to close this gap; the risk of halal products certified by certain certification bodies can be non-halal in other places.

\subsection{Outsourcing Practices}

The cases highlighted focal firms' outsourcing decisions made in order to lower the production cost. Focal firms keep the core process within the firms and outsource other minor processes to some other service provider. Despite acknowledging the benefits of outsourcing practices, such decisions may increase the halal integrity risk when the processes and the controls no longer belong to the focal firm. The outsourcing makes the supply chain longer, which means it is harder for the focal firm to keep track of their quality control process along the supply chain (Lyles et al., 2008), i.e., halal integrity. Similarly, the literature argues that the downstream practices were associated with product based performance in the form of conformance to specifications and durability (Tseng et al., 2008). The insights in the studies show various processes are being outsourced, such as logistics, warehousing, packaging, marketing, and sourcing of skilled and unskilled workers. Even though the firms emphasize the existence of the contract as protection in the interest of both parties, literature identifying the contract can be a subject of violation of organizational norms (Lyles et al., 2008).

Furthermore, the outsourcing practices are likely to increase the untraceable sub-contracting practices by the service provider, which eventually increase the risk of halal integrity. Moreover, the hidden links of the subcontractor are hard to illuminate by the certification mechanism, ultimately a disaster in safeguarding the halal integrity when the over reliance of the halal certificates are seen widely in each case study:

"( $(\cdots)$ we do not do any audit as it is JAKIM role (‥) we just make sure they have halal certificates $(\cdots)$ " (case C).

\subsection{Service}

The involvement of the restaurants and retailers in the halal food supply chain cannot be neglected as halal food requires wholesomeness in its production (Bonne and Verbeke, 2008). During this stage in the food supply chain, the main insight gained from the study regards the service provided by the restaurant. In addition to that, the most critical and fragile component in an effective service delivery system is a human element (Wildes, 2005). On the same note, in halal food production perspectives, in order to minimize the probabilities of human error, a specialized and dedicated group of workers should handle the production (Ab Talib and Johan, 2012).

However, on a realistic level, restaurant jobs suffer from a bad reputation of long hours, low pay, lack of benefits, and hard work (Wildes, 2005). The stigma of the restaurant jobs force the industry to compromise on turnover, which eventually affects the set of labourers who are properly trained at the early stage of employment. This concentrates the halal integrity concern on the risk of human error and cross contamination particularly in a restaurant setting.

\subsection{Logistics}

Halal products should not at any time be contaminated with non-halal products. In this vein logistics is seen as one of the probable sections in the supply chain that has a hidden risk towards halal integrity. Ideally, the vessel of transport needs to be ritually cleaned and consignments properly segregated in order to ensure the requirements are observed and that the logistics are dedicated to the halal product shipment (Jaafar et al., 2011). However, there are very little numbers of certified halal logistics providers to cater for the halal demand. Thus, this suggests that the certification as a solution for the halal food industry is incomplete, therefore halal integrity can be questioned when the logistical risks are yet being mitigated in this area. Interestingly addressing this risk, firm B deploys a strategy of integrating different entities to carry out the logistics roles in the firm:

\begin{abstract}
"We appoint and control our own distributor ( $\cdots)$ the distributor is different entity than us ( $\cdots)$ All information will come from head-quarters such as list of suppliers the distributor can sourced, the specific prices on the supply, types of products, and so on. We dictate the distributor as they are handling on our supply only ( $\cdots)$ if the distributor cannot confirm as halal we change our plans" (case B).
\end{abstract}

\section{MITIGATING HALAL FOOD INTEGRITY RISK THROUGH SUPPLY CHAIN INTEGRATION}

With grounding in the 'farm to fork' concept, the findings indicate the risk of halal food integrity is notable in various echelons in the supply chain. Given the sample of analysis, as the brand owner of the product, the focal firms are held responsible on all acts in their supply chain (Tse and Tan, 2011). In the same essence, the focal firms ideally have total control over the product's supply chain, internal and external of the firm. Seen in this perspective, we categorized the risks into internal risk and external risk. The extenuation of the internal risk is controlled within the walls of the focal firm's factory; meanwhile, the external risk mitigation is associated with the risks that are beyond the focal firm's control. 


\subsection{Leveraging Internal Integration on Internal Halal Integrity Risk}

The interface between the internal halal integrity risk and internal integration is focused within the firm's span of control. For the internal halal integrity risk, it is commonly found during the stages of production, service, food security, and in some of the raw materials' dimensions.

The internal integration practices are detected in all cases through the existence of halal committees within the firms. Even though the 'internal integration' term is unfamiliar for all the cases, the term of collaboration between the departments is highly mentioned. Fundamentally, the halal committee consists of representatives from each department within the local firm. Through the halal committee, the information integration and process integration pertaining to halal food are shared. Moreover, through these internal integration practices, the risk of the internal halal integrity risk can be mitigated by having a better and complete view on the production. Halal food certification is done twice a year by JAKIM. In due course, the halal certifications of some ingredients used during the production may be revoked. It is important for the firms to have this information handy across the department in order to stop the production, to accomplish a product recall process, reduce the cost, and eventually safeguard the halal integrity of the product. Internal integration through halal committee is vital for new product development in addressing the long certification process. Appropriate planning and strategy can be deployed in time. The contaminations due to the equipment, process and storage can be minimized when the input and consideration are discussed for approval by the committee prior being installed. For halal food companies, a common practice is to choose their raw materials suppliers based only on price and halal certification considerations. With internal integration between the departments, each supplier can be audited and the outcome can be discussed during the meeting regarding the price-in such a way that a price-halal integrity ratio can be calculated. Furthermore, views on the demands and business situations can be channelled through the halal committee to mitigate food security concerns. A proper preparation decreases the chances of supply shortage and emergency sourcing can be avoided. Thus, economical and halal integrity related risks can be both mitigated. On the other hand, the halal committee and internal integration can act as the medium of training in understanding the risk related to halal integrity. The higher the understanding being put in the practices, the less probable human error will occur.

\subsection{Leveraging External Integration on External Halal Integrity Risk}

There are only a few external integration practices identified from the study. The remoteness of the external integration is due to the nature of local halal industries which is still immature and incapable of meeting the requirements. Such a shortfall has forced the focal firm to go for imported products. Moreover, due to the geographical distance, regulations applied, culture divergence, and forecasted high possible cost incurred, the decision for the external integration is halted

For raw materials' associated risk, the external integration practised by cases $\mathrm{A}$ and $\mathrm{B}$ evidenced a lessening of the halal integrity risk. Shared information, practices and aims between the focal firms and suppliers resulted in more advantages beyond the halal certification mechanism alone, and overcame the problems with the over reliance on the certification that is prone to be subject to fraud. On the same note, external integration with the regulatory bodies also offers advantages in identifying the risk of fraudulent and misleading information during the supplier selection. Furthermore, the absence of novel traceability tools within the studies can be lessened by having more information regarding the suppliers and their supply chain. Acknowledging the substitution of the traceability tools with external integration strategies cannot be the absolute solution, as external integration cannot offer the same level of technicality. At least through the external integration, the trace of the product can be enhanced to another tier of the supply chain. Furthermore, the external integration increases its visibility in the supply chain. Better traceability and visibility in the supply chain makes for better understanding of the complexity and risk identification, and eventually, the mitigation of the risk.

External supply chain integration is more in-depth than the contractual agreement. Despite the contracts used as instruments to intensify the requirements and parameters, the loss of control of the focal firm cannot be avoided. By contrast, external integration keeps the control within the focal firm even when the agreement is still to be delivered. In this essence, it mitigates the outsourcing risk associated with halal integrity, i.e., hidden sub-contracting. Logistics, as one of the most common processes outsourced, holds a significant halal integrity due to the recurrence of the process along the supply chain. Despite the importance and frequencies of the process within a supply chain, halal dedicated logistics providers still lack behind the demand. The risk of contamination of halal food with non-halal food is high, especially if the proper segregation is not in place. Thus, it is important for the focal companies to tap into the process as evidenced in firm $\mathrm{B}$, for whom mitigating the risk was by controlling a different entity as their sole distributor.

\section{CONCLUSIONS AND FUTURE RESEARCH}

This study truly demonstrates that supply chain integration practice must not be seen short-sightedly; internal and external integration represents a better way 
of mitigating halal food integrity risk along the whole halal food supply chain. As a matter of fact, for focal firms, ensuring halal integrity is a daunting task. Supply chain integration has been able to open a new horizon of mitigating the halal integrity risk. In spite of the remoteness of the supply chain integration practices in the Malaysian halal food industries, and driven by the successful story of supply chain integration in some other industries such as manufacturing, we provide a conceptual understanding of how supply chain integration can work in mitigating halal integrity risk.

The six dimensions of halal integrity risk derived from the study are: production risk, raw material risk, food security risk, outsourcing practices risk, service risk, and logistics risk. The risks' mitigation is then rationalized with supply chain integration practised by the sample. Through the case study, we identified two types of supply chain integration practised: internal integration and external integration in mitigating halal integrity risk, and their advantages in responding to the current control mechanism-halal certification.

Due to the limitations of comprehensiveness, uniqueness and novelty of the halal food industry's emerging market, it has been challenging to discover further integration strategies or to test the results. Thus, we must say that supply chain integration theory offers many opportunities for further research within the same context. Finally, we wish to mention a couple of ideas: we think that this concept can be tested further and the appropriate supply chain integration strategy can be provided for firm guidance in addressing particular risks to halal food integrity.

\section{ACKNOWLEDGMENTS}

The authors thank the anonymous reviewers for their valuable comments and the Ministry of Higher Education Malaysia for funding the studies.

\section{REFERENCES}

Ab Talib, M. S. and Johan, M. R. M. (2012), Issues in halal packaging: a conceptual paper, International Business and Management, 5(2), 94-98.

Berry, B. (2011), Global Halal Food Market, http://www. ats-sea.agr.gc.ca/inter/4352-eng.htm.

Bonne, K. and Verbeke, W. (2008), Religious values informing halal meat production and the control and delivery of halal credence quality, Agriculture and Human Values, 25(1), 35-47.

Bonne, K., Vermeir, I., Bergeaud-Blackler, F., and Verbeke, W. (2007), Determinants of halal meat consumption in France, British Food Journal, 109(5), 367-386.
Dubois, A. and Araujo, L. (2007), Case research in purchasing and supply management: opportunities and challenges, Journal of Purchasing and Supply Management, 13(3), 170-181.

Eisenhardt, K. M. (1989), Building theories from case study research, Academy of Management Review, 14(4), 532-550.

Flynn, B. B., Huo, B., and Zhao, X. (2010), The impact of supply chain integration on performance: a contingency and configuration approach, Journal of Operations Management, 28(1), 58-71.

Frohlich, M. T. and Westbrook, R. (2001), Arcs of integration: an international study of supply chain strategies, Journal of Operations Management, 19(2), 185-200.

Gotzamani, K. D. (2005), The implications of the new ISO 9000: 2000 standards for certified organizations: a review of anticipated benefits and implementation pitfalls, International Journal of Productivity and Performance Management, 54(8), 645-657.

Guerrero-Legarreta, I., Hui, Y. H., Alarcon-Rojo, A. D., Alvarado, C., Bawa, A. S., Guerrero-Avendano, F., and $\mathrm{Wu}$, J. E. (2010). Handbook of Poultry Science and Technology, John Wiley and Sons, Hoboken, NJ.

Jaafar, H. S., Endut, I. R., Faisol, N., and Omar, E. N. (2011), Innovation in logistics services: halal logistics, Proceedings of the 16th International Symposium on Logistics (ISL), Berlin, Germany, 844-851.

Ketchen, D. J. and Hult, G. T. M. (2007), Bridging organization theory and supply chain management: the case of best value supply chains, Journal of Operations Management, 25(2), 573-580.

Lyles, M. A., Flynn, B. B., and Frohlich, M. T. (2008), All supply chains don't flow through: understanding supply chain issues in product recalls, Management and Organization Review, 4(2), 167-182.

Manzini, R. and Accorsi, R. (2013), The new conceptual framework for food supply chain assessment, Journal of Food Engineering, 115(2), 251-263.

Marucheck, A., Greis, N., Mena, C., and Cai, L. (2011), Product safety and security in the global supply chain: issues, challenges and research opportunities, Journal of Operations Management, 29(7/8), 707720 .

Miles, M. B. and Huberman, A. M. (1999), Qualitative Data Analysis: An Expanded Sourcebook (2nd ed.), Sage Publications Thousand Oaks, CA.

Muhammad, N. M. N., Isa, F. M., and Kifli, B. C. (2009), Positioning Malaysia as Halal-Hub: integration role of supply chain strategy and halal assurance system, Asian Social Science, 5(7), 44-52.

Othman, P., Sungkar, I., and Hussin, W. S. W. (2009), Malaysia as an international Halal food hub: competitiveness and potential of meat-based industries, 
ASEAN Economic Bulletin, 26(3), 306-320.

Powell, D. A., Erdozain, S., Dodd, C., Costa, R., Morley, K., and Chapman, B. J. (2013), Audits and inspections are never enough: a critique to enhance food safety, Food Control, 30(2), 686-691.

Ragatz, G. L., Handfield, R. B., and Petersen, K. J. (2002), Benefits associated with supplier integration into new product development under conditions of technology uncertainty, Journal of Business Research, 55(5), 389-400.

Rosenzweig, E. D., Roth, A. V., and Dean Jr, J. W. (2003), The influence of an integration strategy on competitive capabilities and business performance: an exploratory study of consumer products manufacturers, Journal of Operations Management, 21 (4), 437-456.

Roth, A. V., Tsay, A. A., Pullman, M. E., and Gray, J. V. (2008), Unraveling the food supply chain: strategic insights from China and the 2007 recalls, Journal of Supply Chain Management, 44(1), 22-39.

Sroufe, R. and Curkovic, S. (2008), An examination of ISO 9000: 2000 and supply chain quality assurance, Journal of Operations Management, 26(4), 503-520.

Stuart, I., McCutcheon, D., Handfield, R., McLachlin, R., and Samson, D. (2002), Effective case research in operations management: a process perspective, Journal of Operations Management, 20(5), 419-433.

Sumali, A. (2006), Halal: new market opportunities, Proceedings of the 9th Efficient Consumer Response Conference (ECR), Kuala Lumpur, Malaysia.

Swink, M., Narasimhan, R., and Wang, C. (2007), Managing beyond the factory walls: effects of four types of strategic integration on manufacturing plant performance, Journal of Operations Management, 25 (1), 148-164.
Tse, Y. K. and Tan, K. H. (2011), Managing product quality risk in a multi-tier global supply chain, $I n-$ ternational Journal of Production Research, 49(1), 139-158.

Tseng, M. L. and Chiu, A. S. (2013), Evaluating firm's green supply chain management in linguistic preferences, Journal of Cleaner Production, 40, 22-31.

Tseng, M. L., Wu, W. W., Lin, Y. H., and Liao, C. H. (2008), An exploration of relationships between environmental practice and manufacturing performance using the PLS path modeling, WSEAS Transactions on Environment and Development, 4(6), 487-502.

Tuncer, B. (2001), From farm to fork? Means of assuring food quality: an analysis of the European food quality initiatives, IIIEE Reports, 14.

Van der Spiegel, M., van der Fels-Klerx, H. J., Sterrenburg, P., van Ruth, S. M., Scholtens-Toma, I. M. J., and Kok, E. J. (2012), Halal assurance in food supply chains: verification of halal certificates using audits and laboratory analysis, Trends in Food Science and Technology, 27(2), 109-119.

Wildes, V. J. (2005), Stigma in food service work: how it affects restaurant servers' intention to stay in the business or recommend a job to another, Tourism and Hospitality Research, 5(3), 213-233.

Wong, C. Y., Boon-Itt, S., and Wong, C. W. (2011), The contingency effects of environmental uncertainty on the relationship between supply chain integration and operational performance, Journal of $\mathrm{Op}$ erations Management, 29(6), 604-615.

Zsidisin, G., Melnyk, S. A., Ragatz, G. L., and Burns, L. A. (2006), Preliminary findings from a supply risk audit instrument, Proceedings to IPSERA Conference, Lappeenranta, Finland. 